\title{
Container Multimodal Cooperative Transportation Management Information System Based on Artificial Intelligence Technology
}

\author{
Ling Wang' and Shuai Fu $\mathbb{i D}^{2}$ \\ ${ }^{1}$ School of Electronics and Internet of Things, Chongqing College of Electronic Engineering, Chongqing 401331, China \\ ${ }^{2}$ Changchun Humanities and Sciences College, Changchun 130117, Jilin, China \\ Correspondence should be addressed to Shuai Fu; fushuai@ccrw.edu.cn
}

Received 27 August 2021; Revised 13 November 2021; Accepted 23 November 2021; Published 23 December 2021

Academic Editor: Sang-Bing Tsai

Copyright (c) 2021 Ling Wang and Shuai Fu. This is an open access article distributed under the Creative Commons Attribution License, which permits unrestricted use, distribution, and reproduction in any medium, provided the original work is properly cited.

\begin{abstract}
Artificial intelligence is a branch of computer science, which includes natural language, intelligent processing, and professional methods. Since the birth of artificial intelligence, the technology and application fields have continued to grow, and the application fields have also continued to expand. This article aims to study the application of artificial intelligence technology in the management information system of container multimodal transportation and to provide convenient and efficient operation methods for container multimodal transportation. This paper proposes the C-means clustering method. Through the research and development of the terminal management system, it has achieved great success in automation, intelligent planning, and integrated management. At the same time, the EDI system is adopted, which mainly uses the combination of GPS and GIS information platform Internet network technology. Therefore, when evaluating the operation of the multimodal transport virtual container under the control of coproduction, the DEA method is used to operate the multimodal virtual container. The situation is analyzed and evaluated, and the multimodal transport virtual container is determined through investment. The experimental results of this article show that the artificial intelligence system achieves the most efficient multimodal transport management with the most efficient system model, combined with the leading container multimodal transport virtual enterprise, to provide the best way of the management process for the development of the multimodal transport management information system. The intact rate of container cargo during transportation is as high as $99.7 \%$.
\end{abstract}

\section{Introduction}

Before the development of the multimodal transport business, the operators of many transport companies worked independently and created their own systems. Therefore, the work done is very limited. Only after entering the multivehicle business can we expand our business significantly and make more use of our own equipment and materials. Can avoid unnecessary investment in other companies? Due to the development of multiple ships and cross-border transportation facilities, it can be assumed that each supplier can choose the best location and route, establish efficient transportation, improve the level of transportation organization, and coordinate the connection of multiple transmission lines. The carrier will combine multiple modes of transportation to determine the best transportation route and provide a unified transportation document, a unified liability limit, and a unified rate when conditions permit. As a result, cargo owners' demand for more transportation continues to increase, and they are cooperating with international transportation companies to support the development of multiship transportation. With the development of the global econoour, international trade has become more frequent and larger in scale. In order to reduce trade and transportation costs, a large number of companies have chosen packaging as a carrier. In order to achieve the same small cost, container ship owners are willing to further expand the scale of container ships. This requires that the container terminal corresponding to the large containing ship is also getting bigger and bigger. The voyage needs to be deep and long enough to accommodate large enough ships. 
With the continuous and in-depth development of network technology and information technology, the importance of network security management is becoming more and more obvious. Among them, network information management and more general security management are important research topics in the field of network security management. In recent years, the research on artificial intelligence-based network widgets and trust management models has received close attention from academia, government departments, and industries. Governments and enterprises in many countries and regions in the world attach great importance to and invest in research in these two directions. Their progress will continue to promote the progress of scientific and technological equipment and, at the same time, will have an impact on the country and national strength and national security. The open large-scale container transportation system is like a large socio-economic system. It is an open system with multiple functions such as transportation, econoour, and labor. In order to perform these functions, the system must absorb a large amount of material, energy, and moisture from other social systems to increase the system capacity and thereby reduce the negative humidity of the system. On the one hand, only in this way, the multimodal container system can not only maintain normal operation but also develop efficiently and systematically. On the other hand, the multimodal transportation system absorbs the resources and energy provided by the society, and on the other hand, it provides added value and supports its further development with its pioneering life cycle.

The research on the management information system of container multimodal cooperative transportation based on artificial intelligence technology is a very hot research topic. Therefore, many well-known scholars at home and abroad have carried out in-depth research on this topic. The article by Li of the container multimodal cooperative transportation management information system based on artificial intelligence technology integrates the resources of various new cooperation modes and proposes an empty container transportation optimization method based on the participation of container ports; that is, the container port is cooperating with other parties. The role of container leasing companies is used to provide shipping companies with empty container demand [1]. Grobelny P mentioned that multimodal transport is still a growth area of Polish economic activity. In 2015, more than 10 million tons of goods were transported in this way, an increase of $7.5 \%$ over 2014. According to data from the Railway Transport Office (RTO), Poland's multimodal transport accounts for only $2.37 \%$ of the quality of goods transported by rail and $4.53 \%$ of the transport work. Compared with other countries, this makes Poland one of the last places in Europe [2]. The latest developments in You J's intelligent transportation system allow traffic safety research to extend from analysis based on historical data to real-time applications. This research proposes a new method for predicting the likelihood of collisions using traffic data collected by discrete loop detectors and web crawling weather data. The matched case-control methods and support vector machine (SVM) technology are used to identify risk status. Adaptive synthetic oversampling technology is applied to solve the problem of unbalanced data sets. Random forest technology is applied to select influencing factors and avoid overfitting problems [3]. Rahman et al.'s technological innovations over the years have highlighted the operation of enterprise connection organizations and different application platforms. Therefore, a unified management information system (MIS) that can use the Web and promote programming development is needed. The software agent is the latest development of computer software technology, which can be used to quickly and easily build integrated information systems [4]. The proposal of Vilkov et al.'s theory and its subsequent solutions are based on fuzzy set theory, fuzzy logic, and dynamic programming theory. Proposed simple enough algorithm to approximate the problem is under consideration, which can be used for software development. The proposed algorithm is illustrated by conceptual examples [5]. Zhao $\mathrm{M}$ studies the characteristics of climate anomalies under the complex effects of atmospheric circulation anomalies and monsoon systems. His analysis has followed all the basic characteristics of marine logistics and land logistics, but due to the high transportation risk and long transportation time, freight management is different [6]. Zhu's article draws on the research results at home and abroad, introduces an image processing system, uses mathematical modeling optimization methods, and summary induction methods to establish an image processor-based container multimodal logistics safety emergency decision support system research model. The combination of qualitative analysis and quantitative analysis, based on theory, early warning management methods, and emergency decision-making system, made in-depth thinking on the image-based container multimodal transport logistics safety emergency decision support system [7]. There are still many problems encountered in the actual operation process, such as the coordinated deployment of vehicles, the coordination of multiple ports, and the different modes of operation. At the time, the transportation of goods will not be the same. These problems need to be resolved. The domestic research and development of the terminal management system started late, but through the unremitting efforts of our developers, we have made great achievements in automation, mechanization, and high efficiency. China's terminal management is also at the world's top level.

The abovementioned scholars have done a very comprehensive research on the logistics safety of container multimodal transport, but they do not have a good combination with artificial intelligence technology. Therefore, this article will focus on the operation form of container multimodal transport under artificial intelligence technology. An inventory of potential safety hazards is made and, at the same time, certain solutions are proposed to the corresponding problems.

\section{Management Information System of Container Multimodal Coordinated Transportation Based on Artificial Intelligence Technology Method}

2.1. Artificial Intelligence Technology. With the development of the times, the future technological products brought by artificial intelligence will be the "box" of human wisdom. Artificial intelligence can simulate the information process of human consciousness and thinking [8]. Artificial intelligence 
is not human understanding, but it can be considered human and beyond human understanding. Artificial intelligence is a very difficult science. People engaged in this business need to understand computer science, psychology, philosophy, artificial intelligence, engineering, and computer vision. It is a very broad science, covering various fields. For example, in general, one of the main areas of artificial intelligence research is to enable machines to perform certain tasks that require continuous understanding by humans. But different times and different people have different understandings of this "complex task." It shows that through personal design and the application of artificial intelligence [9], the port industry has great expectations for artificial intelligence, and it also shows that Chinese ports can use it to increase competition. Large containers are large in size, mass, and bulk and require special space and equipment for operation during the loading and unloading process. Therefore, the central function of the container is called a container terminal. An important part of cargo transportation is transportation. It is a port where water and land transportation usually goes. Its safety, stability, and excellent performance are the basis for guaranteeing transportation and play a vital role. The modern logistics industry is developing rapidly, and container transportation is the most important tool in international and domestic trade, low cost, large capacity, flexible transmission, etc. These characteristics make it an important part of logistics and transmission [10]. The container industry has become an important indicator to measure a country's logistics level. The Ministry of Transport plays an important role in the country's economic development. With the integration of the global financial system and the rapid development of the global financial system, the era of global logistics is coming. The modern container terminal is not a clean container. It has gradually become a large shipping center and the most important distribution logistics center in the system. Its inherent characteristics give it unique advantages in the logistics system. The rapid development of our country's container terminals has benefited from many factors at home and abroad: domestic economic development, economic transformation, global economic system, international trade growth, advanced machine automation, modern control systems, and international competition [11]. Under the influence of these various factors, the development of container terminals will inevitably develop more efficiently and effectively. The home computer software industry started late, and the research and development of terminal management information systems regressed. Computer intelligence and information management systems are widely used in developed countries, widely used in many industries, and have achieved amazing results in the adoption of modern management systems. Foreign countries have achieved great success in automation, intelligent planning, and integrated management through the research and development of terminal management systems. Information technology is the foundation of understanding. Different conditions can be met. Subsequent business requirements and operational requirements can be implemented objectively and efficiently, delivered on a regular basis, and formulate optimal operating strategies, improve terminal operating efficiency, and save customers time and cost power. The most important function of the terminal control system is automation. Automation is an important production problem through integrated management process, system analysis process, and information process $[12,13]$. Automatic drilling can greatly improve container loading and unloading operations, reduce the intensity of simulation work, and reduce the spread of business risks. This is a successful automation application. Knowledge integration refers to the high degree of dispersion of multiple knowledge and the global optimization of resources.

\subsection{Container Multimodal Cooperative Transportation} Management Information System. Container transportation is a product of transportation renewal and an important part of logistics renewal. Especially, in recent years, multiship transportation has become a transportation organization for international logistics services, and its services and benefits will be reflected and embodied in the industry. Although multilane traffic has been developed for ten years, there are still many problems that are difficult to coordinate [14]. There are many contents and problems in multiapplication transmission systems not only "application" problems but also "software" problems. For the application itself, the problem is mainly focused on the promotion and use of the application, and the software problem is the optimization of the system and the level of use of the application. For this reason, it is necessary to work from the perspective of system integration, so that the system can work more efficiently. Advantages of container multimodal transport is as follows: regardless of the number of transport conditions used to transport goods and the frequency of changes in the goods during transportation, all transport cases are handled by multicarrier operators [15].

The multimodal transport operator is the organizer of the entire transportation. In the multimodal transport, its business procedures mainly include the following links:

(1) Accept consignment applications and conclude multimodal transport contracts

(2) Issuance, pickup, and delivery of containers

(3) Export declaration

(4) Packing of goods and receiving goods

(5) Booking space and arranging cargo delivery

(6) Apply for insurance

(7) Issuing a multimodal transport bill of lading to organize and complete the entire transportation of goods

(8) Customs business during transportation

(9) Delivery of goods

(10) Handling of freight accidents

Among them, the business has better requirements for the overall system design mainly in $1,4,6$, and 3 . It is explained as follows: 
(1) The multimodal transport operator judges whether to accept the consignment application based on the consignment application submitted by the consignor and its own transportation route. If it can be accepted, after the two parties have agreed on the relevant matters, they will sign the copy of the station receipt to the shipper or its agent to prove that the application for consignment is accepted, and the multimodal transport contract has been concluded and started to be implemented.

(4) For the full container of goods packed by the owner, the consignor shall be responsible for transporting the goods to the place specified in the agreement between the two parties, and the multimodal transport operator or his agent shall receive the goods at the designated place. In the case of LCL cargo, the operator receives the cargo at the designated freight station. After receiving the goods, the person receiving the goods on behalf of the intermodal transport operator shall sign the original receipt at the station and give it to the consignor or its agent.

(6) On the shipper's side, cargo transportation insurance should be insured. The insurance is handled by the consignor itself, or the consignor shall bear the expenses and be handled by the multimodal transport operator on his behalf. Cargo transportation insurance can be insured for the entire journey or in sections. In the case of multimodal transport operators, cargo liability insurance and container insurance shall be insured, and the operators or their agents shall apply to the insurance company or in other forms.

The courier only needs to bring a transfer contract and a safe. If the baggage is lost or damaged during transportation, the multivehicle operator will be responsible for all transportation, and the transfer of each transportation component will be responsible for the damage of its own transportation part. Most ships use containers as a means of transportation to directly complete the transshipment. After the goods are stored in the manufacturer's office or shop, they can be directly shipped to the shop owner's office or shop. Due to the use of fitness equipment for loading and unloading during transporting, and the luggage in the box is not affected, luggage damage, luggage accidents, and luggage theft are greatly reduced, thereby improving the quality of luggage to a certain extent. In addition, due to the close cooperation and close connection of multiple transportation systems in many aspects, the speed and transit time where the goods go reduce the loading time of many goods, thereby ensuring the safety, speed, and accuracy of the goods [16]. Multimodal transportation can improve the level of transportation organization, realize integration and integration, and improve the connectivity between different transportation systems. Before the development of multimodal transport, operators of many shipping sites worked independently and made their own plans.
Therefore, the length of business is limited, and the scale of freight is also limited. However, once different transportation companies join multivehicles, it can greatly increase the scale of service operations, increase the impact of available equipment, and choose better transportation routes and arrange appropriate transportation. With the development of the global econoour, international trade has become more frequent and larger in scale. In order to reduce trade and transportation costs, a large number of companies have chosen packaging as a carrier. In order to achieve the same small cost, container ship owners are willing to further expand the scale of container ships. This requires container terminals corresponding to large container ships to become larger and larger $[17,18]$. Cruise ships need to have deep and long enough scenes to transport large container ships. The opening of the container handling system also proved internally that this operation requires a large amount of information exchange. Compared with sea transportation, a large amount of information exchange is also required for the terminal or transportation to accurately obtain its precise positioning to ensure the efficiency of transportation. The plan is to exchange information with the two main departments as follows: the first is production, planning, operation, transportation, and related procedures, rules and regulations, etc. The second is the distribution and demand of related commodities, national and regional policy information, policy information, product information, policy and regulation information, special technical information, etc. The information exchanged between programs and regions, for example, should provide multivehicle transportation systems with transshipment capabilities to the environment [19] and collect information such as time changes and transportation information through supply and demand updates to ensure the normal operation of the multibox transshipment system. The artificial intelligence industry started late, and the development of terminal management information systems is relatively slow. Computer intelligence and information management systems are widely used in developed countries, widely used in many industries, and have achieved amazing results in the adoption of modern management systems. Foreign countries have achieved great success in automation, intelligent planning, and integrated management through the research and development of terminal management systems. Information technology is the foundation of understanding. Different conditions can be met. Subsequent business requirements and operational requirements can be implemented objectively and efficiently, delivered on a regular basis, and formulate optimal operating strategies, improve terminal operating efficiency, and save customers time and cost motivation. The most important function of the terminal control system is automation [20]. Automation is an important production problem through integrated management process, system analysis process, and information process. Automatic drilling can greatly improve container loading and unloading operations, reduce the intensity of simulation work, and reduce the spread of 
business risks. This is a successful automation application. Knowledge integration refers to the high degree of dispersion of multiple knowledges and the global optimization of resources.

\subsection{Algorithm of the Management Information System of} Container Multimodal Coordinated Transportation Based on Artificial Intelligence Technology. On the basis of explicit C partition, the $\mathrm{C}$-means clustering method cannot be obtained [21]. The C-method shown in the set method reduces the category variation to an area function [22], and the mathematical model is defined as follows:

$$
v_{1}=\frac{1}{\left|s_{1}\right|} \sum_{s_{1} \in x_{1}} x_{k} i=1, \ldots, c,
$$

where $v$ represents speed and S represents mileage

$$
\min z(U)=\sum_{i=1}^{c} \sum_{k=1}^{m} \mu_{k}\left\|x_{k}-v_{k}\right\|^{2} .
$$

The result of cluster analysis of items using the C-mean clustering method is that one item belongs to one category. In cluster analysis, when the impact factors required for planning and their degree of impact have been fully determined [23], The algorithm can also be used in the calculation of the container scheduling problem of the terminal, which can effectively improve the scheduling efficiency. The C-means cluster analysis method can be used, as shown in the following formula:

$$
\begin{aligned}
M_{f_{c}} & =\sum_{k=1}^{n} \mu_{k} x_{k}+\sum_{k=1}^{n} \mu_{j} . \\
d_{k} & =\left[\sum_{j=1}^{n}\left(x_{k j}-v_{k}\right)^{2}\right]^{1 / 2} .
\end{aligned}
$$

If several cluster center vectors are known, the Euclidean distance between $x$ and the cluster center vector $v$ is as follows:

$$
\begin{aligned}
& W=\sum_{k=1}^{n} \sum_{v=1}^{p} \eta_{k}\left(d_{v c}\right)^{2} \\
& v_{1}=\sum_{k=1}^{n}\left(\mu_{i k}\right)^{m} X_{k} \cdot \sum_{k=1}^{n}\left(\mu_{k}\right) U \in M_{f_{c}} .
\end{aligned}
$$

Based on the C-split fuzzy division, the C-split fuzzy method can be obtained. The $\mathrm{C}$-method simulation function is also a cluster analysis method, which can reduce the category variability as a quality function [24]. An example of the C-means compression function is as follows:

$$
\begin{aligned}
\left\|x_{k}-v_{1}\right\|_{G}^{2} & =\left(x_{k}-v_{i}\right)_{T} G\left(x_{k}-v_{1}\right), \\
\left\|x_{k}-v_{i}\right\|_{G}^{2} & =\left\|\left(x_{k}-v_{1}\right)\right\|^{2}+\sum_{n=1} i=2 .
\end{aligned}
$$

Through the above formula, it can be concluded that the fuzzy C-type mean clustering method can be expressed as the following mathematical program:

$$
\begin{aligned}
\min z(U, V) & =\sum_{i=1}^{c} \sum_{k=1}^{n}\left(\mu_{i k}\right)^{m}\left\|x_{k}-v_{1}\right\|^{2}, \\
z(U, V) & =\sum_{i=1}^{c} \sum_{k=1}^{n}\left(\lambda_{i}\right)\left\|x_{k}-v_{i}\right\|^{2}+\mu\left(\sum_{i=1}^{c}-1\right), \\
v_{i} & =\sum_{k=1}^{n}\left(\mu_{k}\right)^{m} x_{k} \times \sum_{k=1}^{n} \varpi_{k}^{m} .
\end{aligned}
$$

Due to the factors that affect the design and construction of container components, there is a certain degree of uncertainty and attention in the information and description collection process [25], so the average clustering method is selected to read the configuration of container components $v$ and $x$.

$$
\begin{aligned}
v_{1} & =\frac{\sum_{k=1}^{n}\left(\mu_{k}\right)^{m} x_{k}}{\sum_{k=1}^{n}\left(\mu_{k}\right)^{m}} i=1,2, \ldots, c, \\
\mu_{k} & =\frac{\left(1 /\left\|x_{k}-v_{i}\right\|_{g}^{2}\right)^{1 / m=1}}{\sum_{j=1}^{c}\left(1 /\left\|x_{k}-v_{i}\right\|^{2}\right)} .
\end{aligned}
$$

The purpose of studying transportation output is to determine their impact on total output and total input. Among them, the structural effect refers to the impact of other factors, especially changes in the input system, on the total output. When the total amount remains the same or the production system remains unchanged, the total output remains unchanged. Through the total investment $I$, on the premise that there is a proportional growth relationship $\mathrm{P}$ between input and output, the above definition is expressed by a mathematical model:

$$
\begin{aligned}
& \triangleleft P=\sum\left(P_{0} \frac{I_{2}}{I_{0}}\right)-P_{0} \frac{I_{2}}{I_{1}}, \\
& \triangleright I=I_{0} \frac{P_{i}}{P_{0}}-\sum\left(I_{0} \frac{P_{i}}{P_{0}}\right)^{2} i=1,2,3 .
\end{aligned}
$$

To use the calculation of structural effects to guide the structural adjustment of a multitool system, we must first identify which institutional effects are signs of structural optimization. The concept of optimization is to use many transmission conditions and find the optimal area $q$. The actual use range of parameter $p$ is (0.08-3.97), the range of $V$ is (36.7-42.9), and the range of $S$ is (697-1182).

$$
\begin{gathered}
\triangleleft P_{1}=P_{0}-P_{0 i}+P_{i} \frac{I_{n}}{I_{0}}-P_{0} \frac{I_{0}+I_{i}}{I_{2}}, \\
f_{j}^{l}=\frac{q_{j} h_{k}^{j}}{\sum_{r} h_{j}^{0}}+\frac{q_{j} \exp (-\theta c)}{\sum_{r} \exp \left(-\theta c_{j}^{r}\right)} .
\end{gathered}
$$


Theoretically speaking, $k$ has a maximum value, and $p$ that satisfies the maximum value of $k$ is the optimal probability value of multimodal transport distribution. The following formula can be derived:

$$
\begin{aligned}
k & =-\frac{\sum_{r}\left(p_{\mu}^{r} 1 n p_{j}^{r}-p_{\mu}^{r}\right)}{\sum_{r} p C_{\mu}^{r}}, \\
\frac{\partial k}{\partial p_{h}^{r}} & =\frac{-1 n p_{j}^{r}\left(\sum_{r} p_{y} c_{x}\right)+c \sum_{r}\left(p^{2} 1 n p_{j}^{r}-p^{2}\right)}{\left(\sum_{r} p_{i}^{r} c^{2}\right)}, \\
\frac{1 n p_{j}^{r}}{C_{j}^{r}} & =\frac{\sum_{r}\left(p_{j}^{r}-1 n p_{h}^{r}\right)}{\sum_{r} p C_{k}^{2}} .
\end{aligned}
$$

\section{Experiments on the Management Information System of Container Multimodal Coordinated Transportation Based on Artificial Intelligence Technology}

While global trade has enabled the continuous development of the global econoour, it has also enhanced the competitiveness of container terminals in the global econoour. The scale of the entire container trade industry has dropped by $37.6 \%$, shipping has decreased by $60 \%$, and the utilization rate of terminals around the world has also shown a cliff-like decline. Even in the face of the global economic crisis, the economic crisis of container trade has become more serious. In recent years, the development of our country's container terminal culture has slowed down, which has already touched the bottleneck of industrial development. Faced with this situation, the country has issued corresponding policies to deal with it. Under the new policy format and new policies, the terminal industry is facing a world and challenging situation. On the one hand, some of the best companies can stand out from the competition, continuously improve facilities and management, and promote healthy growth; on the other hand, competition forces companies to continuously improve, increase productivity and performance levels, improve management systems, reduce operating costs, and improve enterprises the ability to avoid risks. For a combination of multiple transmission capabilities, a single mating cable is not enough. The importance of the matching base lies in the self-regulation of the transmission capacity among many transmission systems. However, the econoour is constantly developing and developing, and the demand for transportation is also growing, then adapting to the oral system. For multimode payload requirements, the corresponding process is also static. The development process is to make up for this defect and is also an important basis for the balance of power and energy [26].

3.1. Experimental Description and Experimental Strategy. Thanks to the precise control function of the container control system, the terminal runs smoothly. With the continuous change of business, the function of the terminal control system also needs to change constantly, and the control system also needs corresponding changes, which puts forward the highest requirements for the function of the system. However, the system has always focused on a common location in the design process and is unlikely to be useful when dealing with new situations that affect terminal performance. In this case, the developer needs to consider whether the project manager has the ability to adapt to changes during the development process. Before developing an information system, it is necessary to analyze the information processing function, construct system architecture, levels, functional modules, and related processes. This problem needs to be subdivided from surface to space, from process to perspective, from top to bottom, etc., in order to evaluate the effectiveness of the program. System performance requirements are analyzed through system analysis. First, the research objectives and the performance requirements are determined through objective research objectives. The research subjects have a wide range of requirements, strong professionalism, and rich experience. It should include managers, professionals, engineers and technicians, customer personnel, and other personnel who design program information. Second, what is being studied is determined, including people, things, and the relationship between the two. The functional requirements of the program can be understood through human research, the functional basis of the program can be understood through the study of the object, and the functional relevance of the program can be determined by the relationship between people and objects and between people. Then, there is the research method, and the most accurate research method is used through the process of the most extensive procedural activities, levels, and relevance. The final step is to wisely choose the size of the work through their expertise, remove the excess size, and determine the length of the subject work required to determine the key size. Successful system performance analysis can ensure that a well-designed system is optimized, managed, and fully functional.

3.2. Sample Collection. The container terminal management system is not a simple data management system. Through this system, the intelligent transmission function of the junction box can also be realized. It is a highly automated and intelligent system that can improve machine efficiency and reduce unnecessary workload. The intensity of simulation work is reduced, the production process is shortened, work efficiency is improved, and continuous performance is achieved under certain requirements. While improving performance, it also saves time and cost for customers. The types of these materials are not uniform for containers that run multiple fitness applications, and the technical indicators and operating parameters may be completely inconsistent. The parameter indicators in similar applications may be incompatible, which makes many information processes in information sharing. And this knowledge is effective. This is the problem of "knowledge islands." And with the development of the terminal, not all facilities should be added and constantly updated, which means that "information 
islands" will continue to form, which will significantly affect the digital structure of terminal containers. The lack of full automation of business operations and terminal services and no knowledge can reveal the benefits of the program.

3.3. Experimental Results and Data Analysis. The automation and understanding of traditional terminals is a new trend. Unlike fully automated terminals, the automatic conversion of traditional container terminals must plan for existing investments to avoid affecting business growth. Finding a low-cost method can also identify exercises on this basis. This is a challenge that every traditional container terminal must face now. Therefore, the intelligent tally system extended by artificial intelligence technology came into being, and its working principle is shown in Figure 1.

The artificial intelligence application system controls and recognizes the path required by the camera monitoring system; the monitoring system sends video to the recognition equipment. The recognition machine knows the box number, box type, line number, and operation information of the expert tally application. The artificial intelligence system application server sets the CTOS system to verify whether the operation is feasible. The smart tally application server notifies the winch driver, cable operator, and service information management personnel through voice. The recognition machine recognizes the service information to the smart tally server. The smart tally application server automatically installs CTOS and writes automatically enter the current operating procedure. The intelligent tally application server will display external information on the client interface, and the tally staff will manually intervene as shown in Figure 2.

In order to transport containers, we need to check the characteristics of the flow of goods. The impact of seizure on the flow of goods is analyzed by simple cargo flow patterns in container transportation and cargo organization. The migration of related goods depends on the transportation regulations of many countries and the economic and local conditions of each transportation system to determine diversification and distribution methods and distribution systems. Because container transportation is based on largescale production methods, we must first sort out the small product resources scattered on the ground, as shown in Figure 3.

There are two direct reasons for the institutional changes of the multimodal transport system in the new era: on the one hand, the different ways of demand in the new era and the promotion of growth, each of which ushered in a new era. The growth change of "spontaneous growth" explained by the expansion of the transfer rate has also changed the system; on the other hand, because the first transfer method cannot adapt to the development needs of the new period and new situation, the transfer rate transfers between different systems, that is, competition and substitute. The survey on customer service satisfaction and benefit improvement is shown in Table 1.

As shown in Figure 4, in recent years, the scale and quantity of global container transportation have been increasing at a rapid rate. From 2016 to 2020 , the growth rate of container cargo transportation in the world and in various regions of mainland China is shown in Table 2.

Prior to this, a container network has been formed with international ports, regional ports, transit ports, and ports as fragments, connected by the global trunk and branch lines. In order to compete in the container shipping market, shipping companies operating in the container market face potential market competition and continue to combine, configure, and adjust to purchase large container ships. Large container ships use economies of scale to improve service quality, reduce costs, and increase competition. Here, the comprehensive rankings of the world's major container companies in recent years are shown in Table 3and Figure 5.

By analyzing the current rankings of major container companies in the world, we can understand their container assembly situation and use artificial intelligence to learn, assemble, configure, and adjust to purchase large container ships. Large container ships use economies of scale to improve service quality, reduce costs, and increase competition [27].

In order to better illustrate the important role of mean fuzzy clustering in the layout of the container multimodal transport system, we enumerate the total domestic freight value here as shown in 4 .

The clustering algorithm is used to verify whether the compact cluster analysis can be used to verify the layout of containers composed of a multilane transportation system. Then, the more cities selected according to the characteristics of the method, the better the effect of cluster analysis; in addition, there are many indicators that affect the rating. Therefore, the selection of evaluation indicators in the future research process also requires in-depth planning as shown in Figure 6.

During transportation, if the product needs to be placed in the container cargo scanning area, the pallet containing the product should be moved to the waiting area in the warehouse; the operator uses the password catcher to scan the item box password, collect outgoing information, and check the information and the store list whether the information is valid, if it is invalid, it should be processed manually as soon as possible. The technique is shown in Table 5.

The flowchart of the transportation process is shown in Figure 7.

Larger ports need to face different shipping companies, often have agents in many ports, and need an EDI system that serves the shipping companies themselves and passes through multiple ports. Even within the same port range, the same sender may be in contact with different terminal companies.

The EDI system refers to a system that can automatically transmit and process business documents such as orders, invoices, and invoices among enterprises through a communication network. The communication network is the means to realize EDI. EDI involves many departments and industries, such as related companies, banks, insurance and commodity inspection, customs, and transportation. EDI first established a dedicated network among trading partners [28]. 


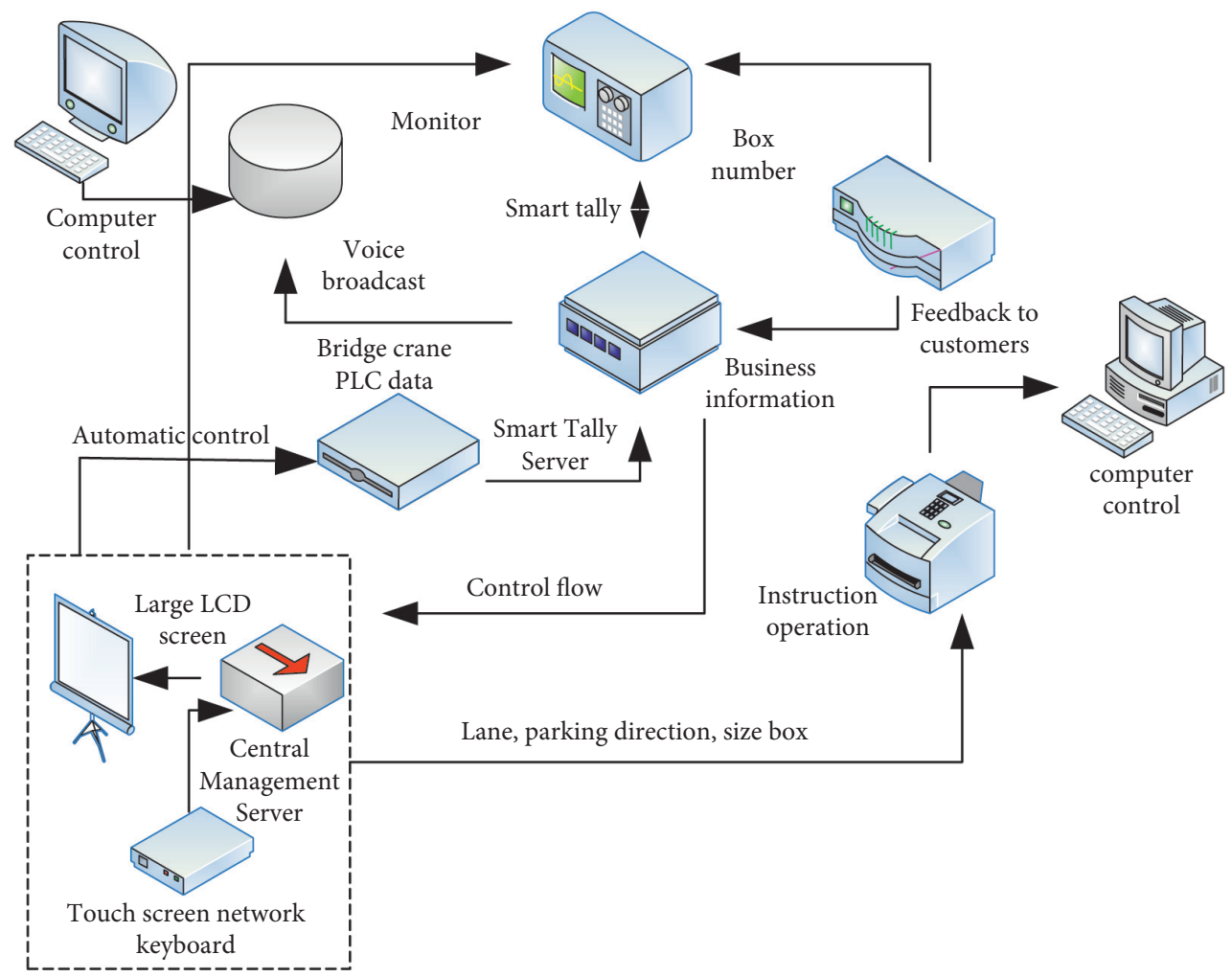

Figure 1: Key data flow of the smart tally system.

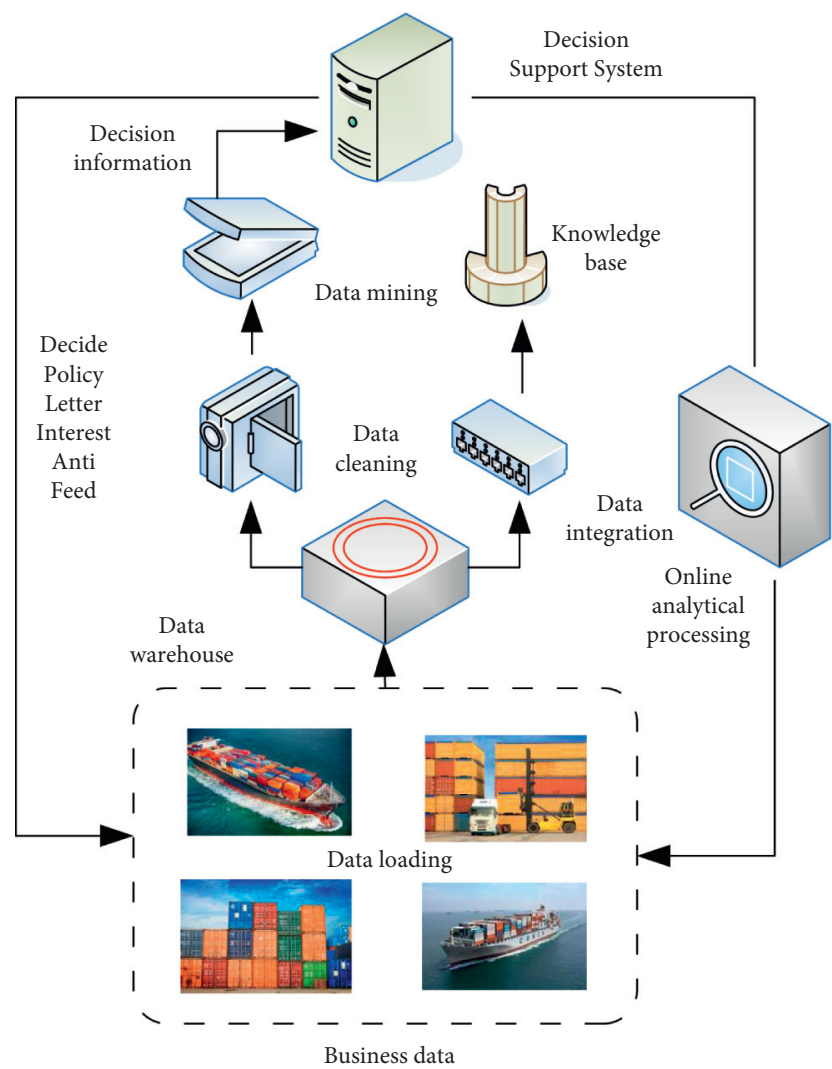

FIgURE 2: The overall architecture of the artificial intelligence tally system.

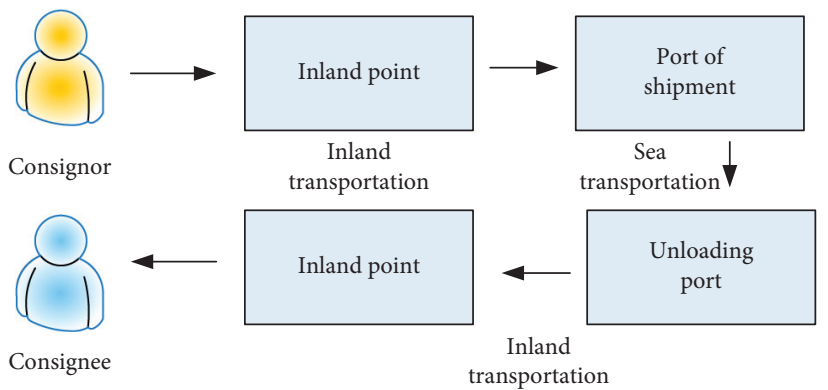

FIgURE 3: Example of container transportation.

TABLE 1: Survey results of customer service satisfaction and benefit improvement.

\begin{tabular}{lcc}
\hline Company name & $\begin{array}{c}\text { Service } \\
\text { satisfaction }\end{array}$ & $\begin{array}{c}\text { Benefit improvement } \\
(\%)\end{array}$ \\
\hline $\begin{array}{l}\text { Maersk land and sea } \\
\text { Mediterranean }\end{array}$ & 8.7 & 37 \\
shipping & 6.9 & 32 \\
Evergreen shipping & 9.1 & 22 \\
\hline
\end{tabular}

In fact, there is a many-to-many relationship among the topics of container transportation information exchange as shown in Figure 8.

On the whole, container transportation based on artificial intelligence multimodal transportation is not limited to only one port. Therefore, a container transportation system that can provide value-added services is established, 

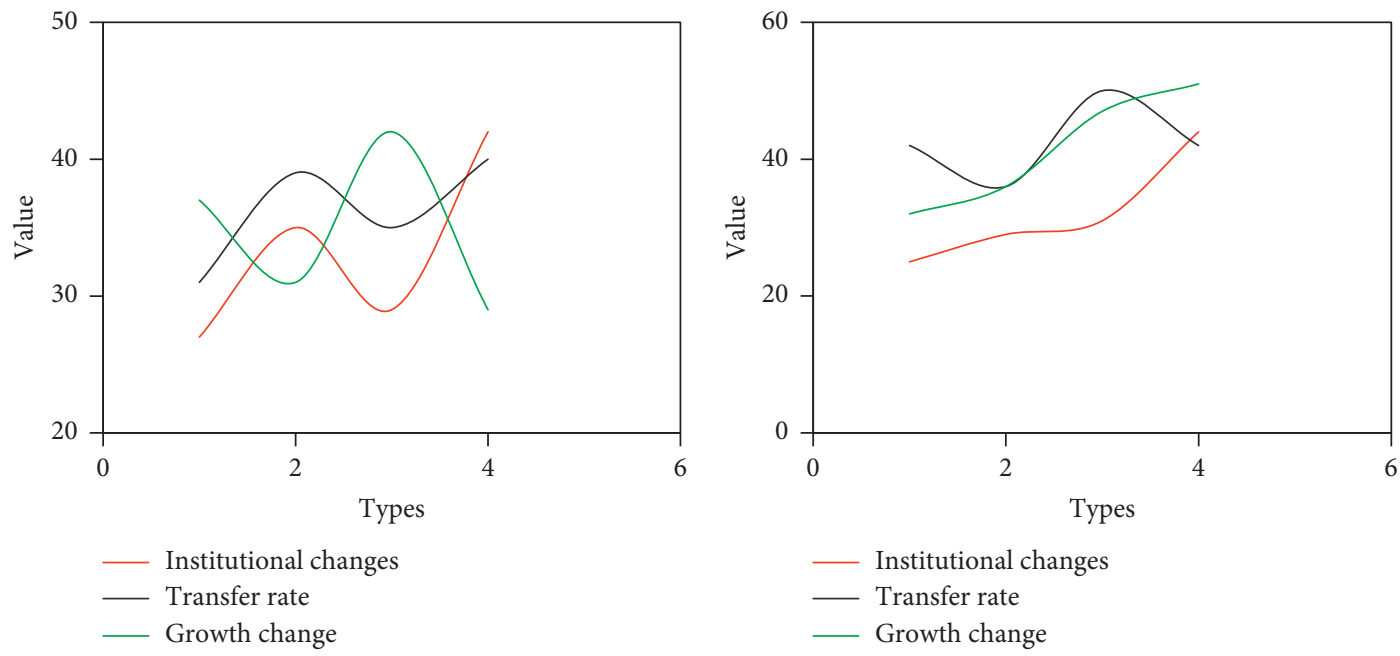

FIGURE 4: Reasons for institutional changes of the multimodal transport system.

TABLE 2: World transportation growth rate (\%) from 2016 to 2020.

\begin{tabular}{|c|c|c|c|c|c|}
\hline & 2016 & 2017 & 2018 & 2019 & 2020 \\
\hline Annual growth rate of world container trade volume & 11.0 & 12.0 & 11.6 & 9.6 & 8.2 \\
\hline World container shipping capacity growth rate & 7.0 & 8.0 & 7.1 & 7.5 & 6.6 \\
\hline Growth rate balance & 3.0 & 4.0 & 4.5 & 2.1 & 1.6 \\
\hline
\end{tabular}

TABLE 3: Ranking of the world's major container companies.

\begin{tabular}{lcccc}
\hline The company & Rank & Market share (\%) & Total TEU & Total number of ships \\
\hline Maersk land and sea & 1 & 12.3 & 31214 & 355 \\
Mediterranean shipping & 2 & 7.2 & 42351 & 295 \\
Evergreen shipping & 3 & 6.1 & 33678 & 278 \\
\hline
\end{tabular}

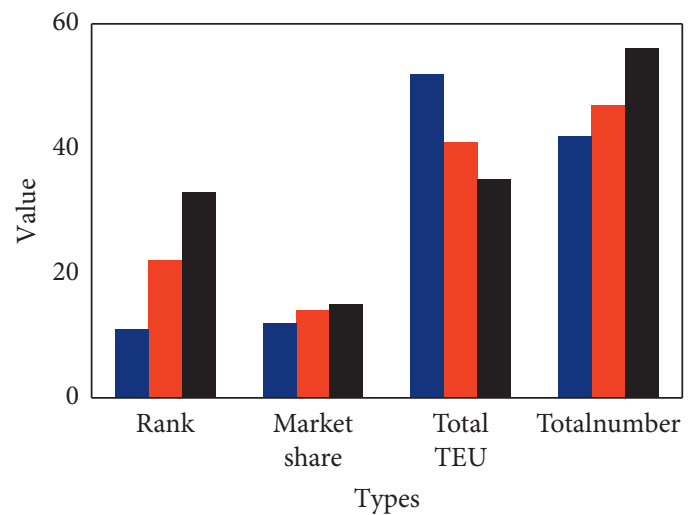

Maersk-land and sea

- Mediterranean Shipping

- Evergreen Shipping

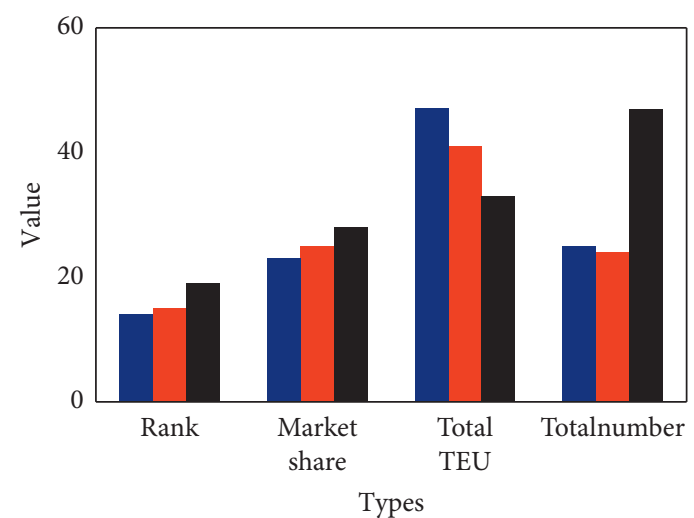

Maersk-land and sea

- Mediterranean Shipping

- Evergreen Shipping

FIGURE 5: Information of the world's major container companies.

TABLE 4: Fuzzy clustering center (100 million yuan).

\begin{tabular}{lccccc}
\hline$M=1.5$ & GDP & Total social consumption & Investment in fixed assets & Total freight & Policy orientation coefficient \\
\hline First category & 4698 & 5602 & 14560 & 5689 & 4951 \\
Second category & 991 & 964 & 14235 & 4512 & 3256 \\
Third category & 201 & 456 & 11784 & 5261 & 3145 \\
\hline
\end{tabular}




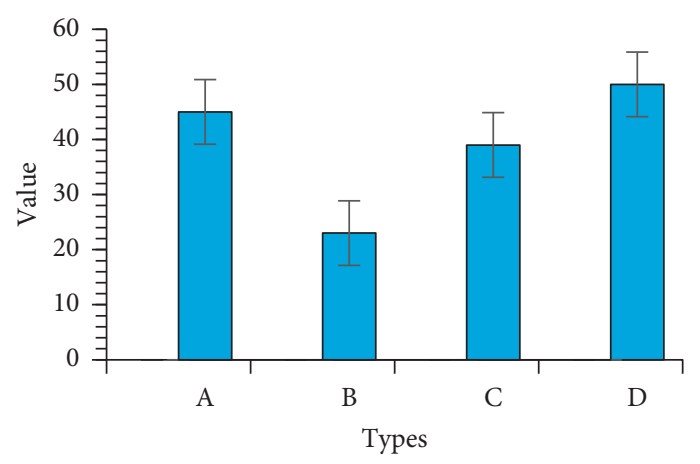

Clustering algorithm

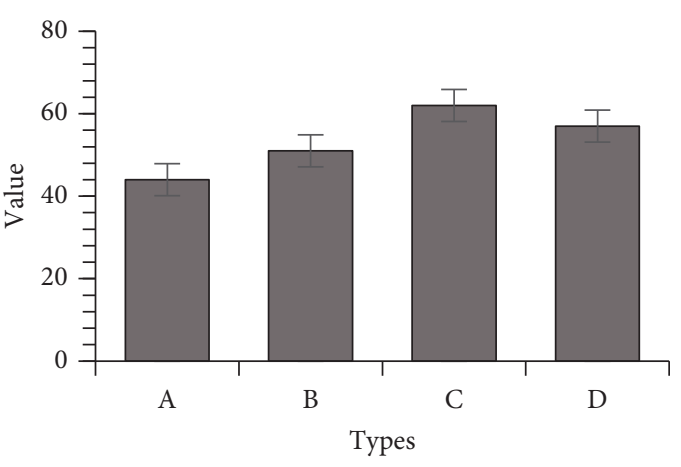

System layout

FIgURE 6: Usage of the clustering algorithm.

TABLE 5: The cost of introducing barcode technology.

\begin{tabular}{lccc}
\hline Assets & Unit price & Number & Service life \\
\hline Pos scanner & 200 & 50 & 10 \\
Barcode printer & 550 & 12 & 5 \\
Barcode & 0.05 & 1000 & 7 \\
\hline
\end{tabular}

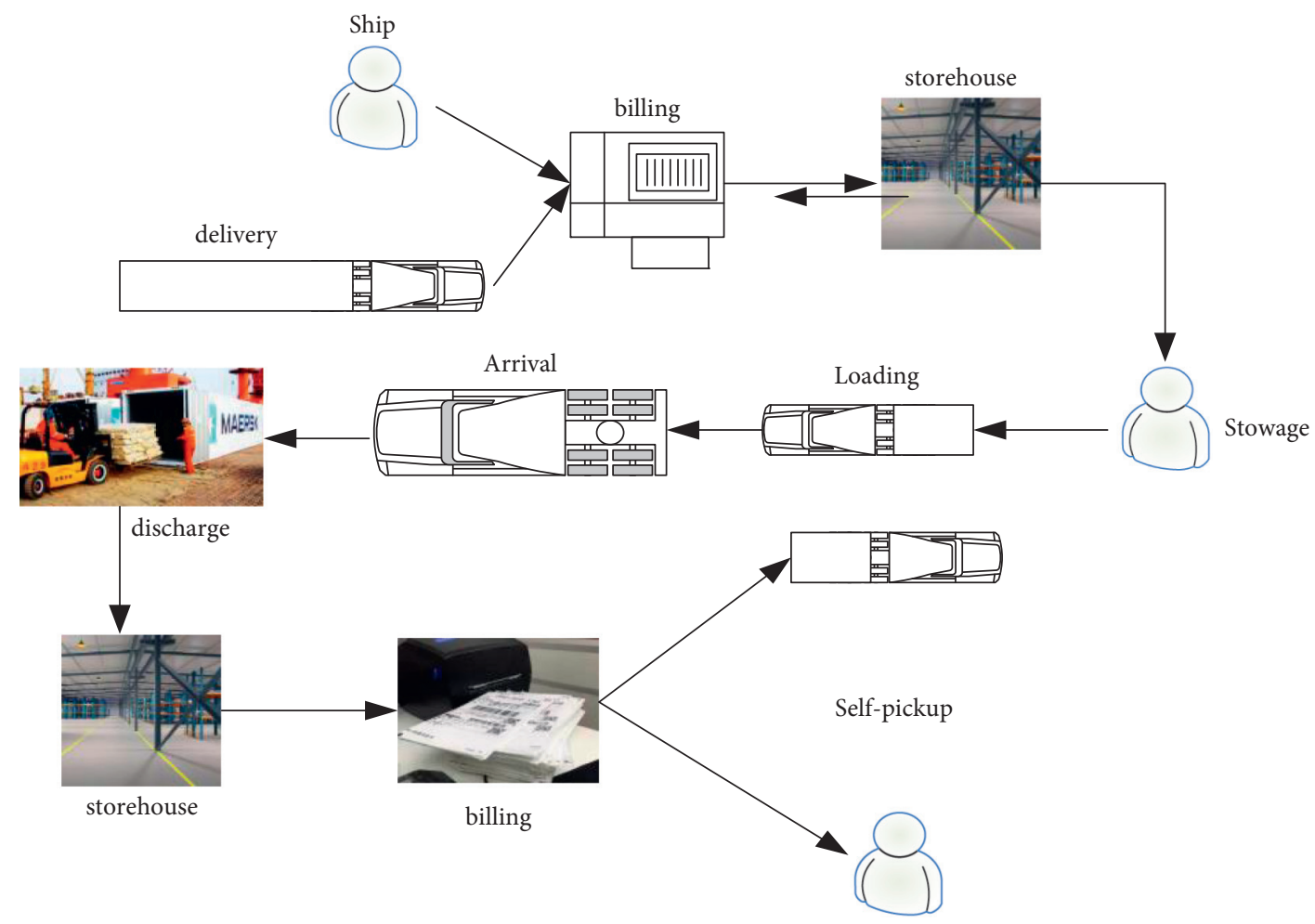

FIgURE 7: The flowchart of the transportation process.

and it is connected with the national transportation system and the international public data network.

The realization of port integration requires the role of many factors, generally speaking, including port natural resources, differentiation between ports, information platforms, human resources and investment and financing, administrative mechanisms, market functions, supply chain business integration, and logistics network, etc. It is mainly for the following points:
(1) The natural resource characteristics of ports lead to the division of port functions

(2) The differences among ports are mainly reflected in two aspects: first, time (including inland transportation time and stay time in port) and service quality. Second, the difference in port service products is a key consideration that ports need to consider in the process of port competition 


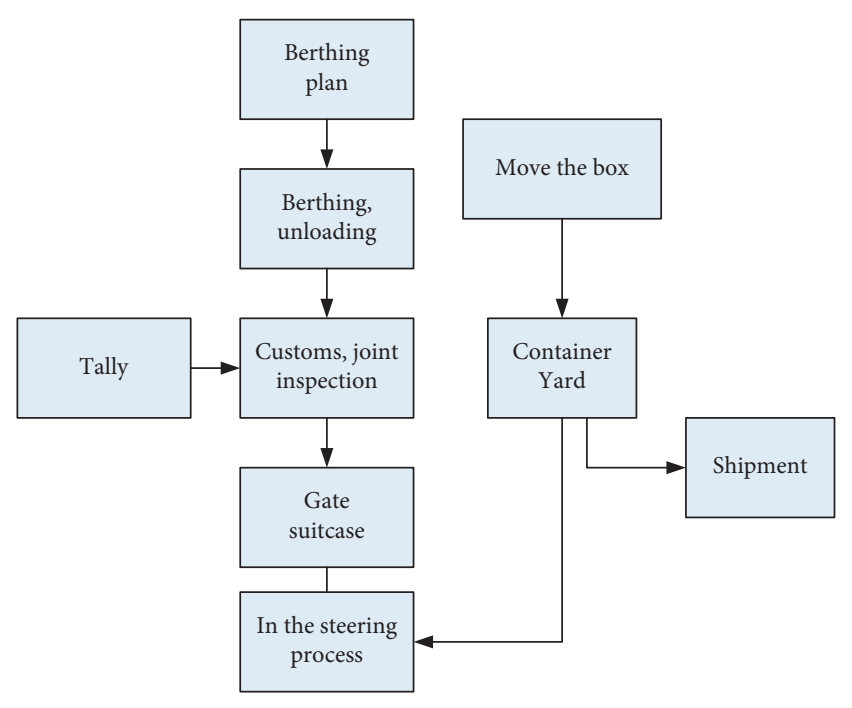

FIGURE 8: EDI system in multiple ports.

(3) Building an information platform shared among regional ports is a technical guarantee for port integration. In the process of building a shared information platform, the main task is to establish an information sharing mechanism, unify information platform standards, and realize the docking of regional information platforms

(4) In the process of port integration, especially the integration of cross-regional ports, the interests of various administrative regions inevitably conflict. In order to alleviate the conflicts of various administrative regions, we need a unified administrative management agency and administrative coordination agency to establish an appropriate coordination mechanism to balance the interests of all parties [29].

Combining this will enable our country's container multimodal transport to be integrated and further in line with international standards as shown in Figure 9.

The module sharing of the information system should not only be based on the specific commercial needs of the container terminal but also be linked to the actual mailing system of the container terminal. According to the operating content and conditions of different parts of the container, the control system is divided into six parts: customer management system, electronic system, statistical data request system, transmission information system, overhead system, and payment management system. The system adopts a distributed system, and each partition can access and work independently, or call each other through a command as shown in Figure 10.

We use total transit time, total transit rate, and input indicators as active indicators to transfer data on average revenue, container loading stability rate, the annual growth rate of container transportation, and other virtual corporate organizations. Here, we choose the total transfer rate and input indicators as the active indicators, and the use of excess investment for correlation is to analyze and solve the input and output problems of the enterprise. In the actual use process, the multimodal transportation is carried out by using the EDI system, combined with the GPS and GIS information platform Internet network technology, to ensure the accuracy of coordinated transportation. Therefore, excess investment and DEA indicators can be easily resolved. This question is shown in Figure 11 and Table 6.

\section{Discussion}

The current information collection technology is divided into time-based information collection technology and site-based information collection technology according to static and energy information. Generally speaking, the entire mass transportation process, that is, the multimodal transportation process, is divided into two parts: "private area exploration" and "track-track discovery." The route station is based on the frame and mainly uses time information technology; the route tracking is mainly based on the transportation means using field-based information technology. At the same time, in order to achieve visual effects, the system mainly uses the combination of GPS and GIS information platform Internet network technology to determine the information management between the operator and the operator and the manager, and broadcast the information in real time. The response method is improved based on the actual transportation situation, including emergency information such as location, time, and speed. The information system corresponding to the multimodal transport system includes the empire information system and the back-end technology of the multimodal transport container transfer. Due to the general lack of understanding of multivehicle transportation, the control cannot cancel the previous control mode. Therefore, we can modify the previous multivehicle intermodal transportation control method, by increasing the overall planning between multiple vehicles, planning the dispatch time, and the problem of train number information, so as to solve the problem of multivehicle high-efficiency intermodal transportation in the actual transportation process. Under the previous economic system, especially under the influence of the related concepts of "large and complete, small and complete" in state-owned enterprises, there are certain deficiencies in the management concepts, managers, and operators of logistics companies. And the thinking of related logistics companies does not fully understand the role of packaging and does not have a clear understanding of the operation of the multiship transportation process. Therefore, manufacturing companies do not have enough coping methods and practical solutions. The severity of the problem has led to a low degree of integration between logistics and transportation. Surprisingly, it is impossible to establish a large and professional service system. Multiple passport documents can also be used to gather information during testing at certain locations. The multivehicle license is issued by the multicarrier or its 


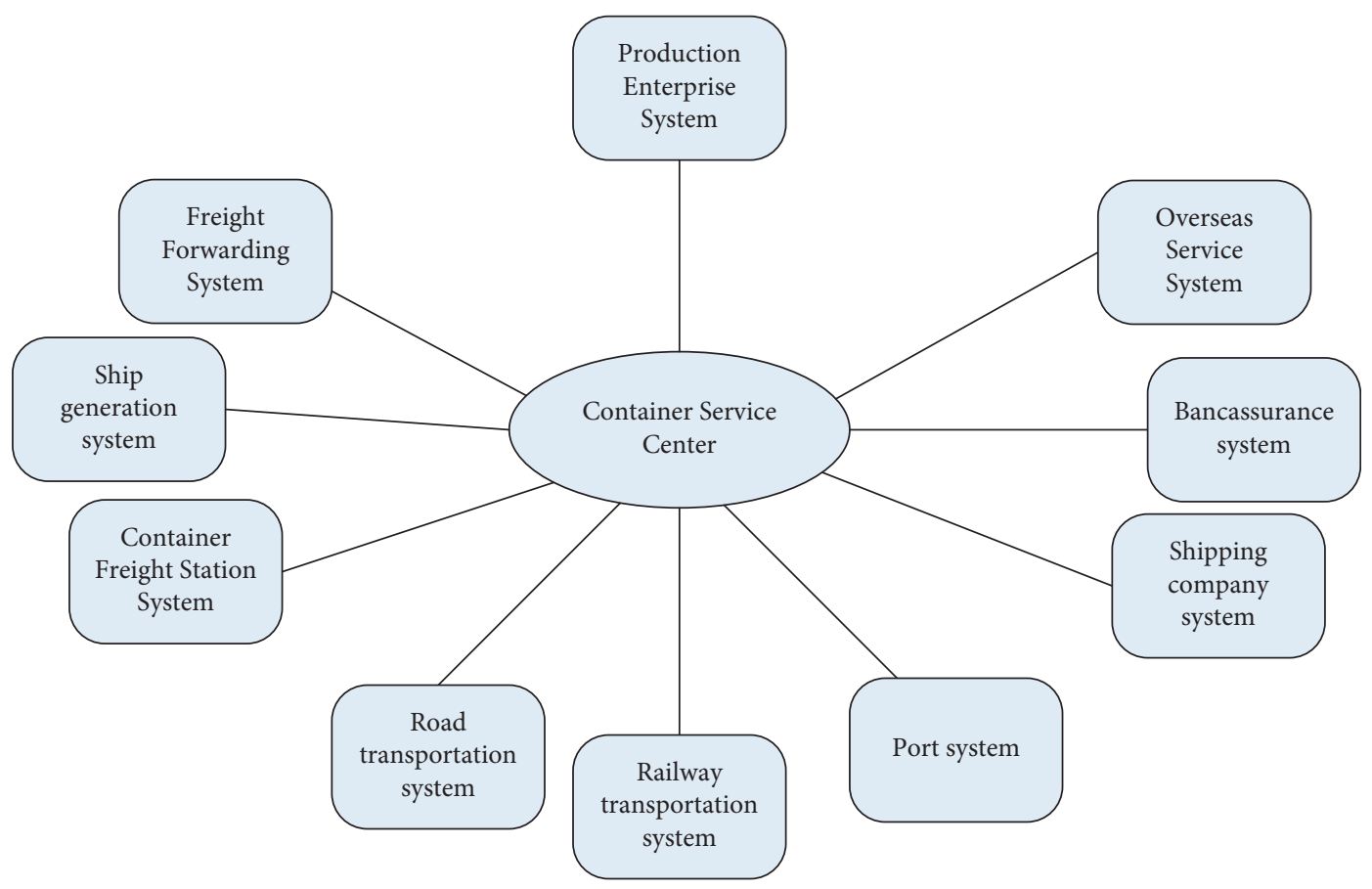

Figure 9: Container system diagram.

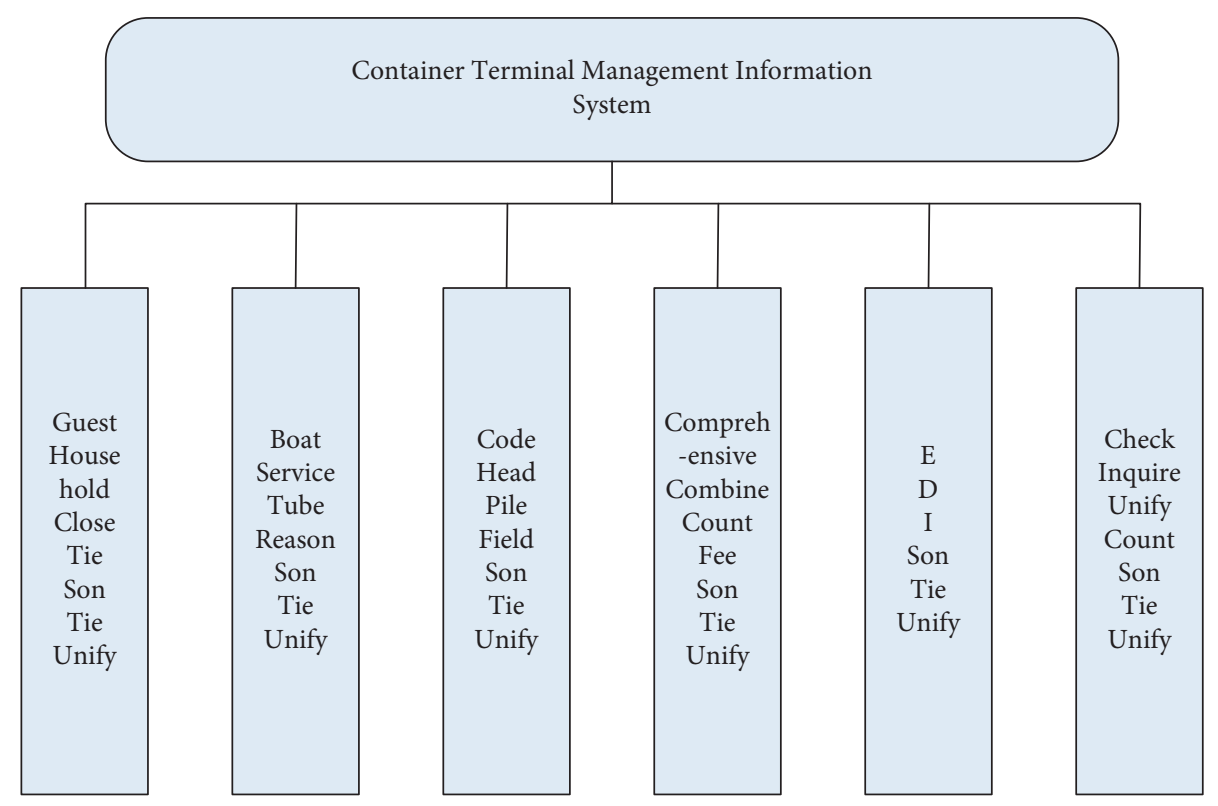

Figure 10: System submodule.

agent, certifying that the multimodal transport contracts that the goods are received and transported by the multicarrier, and the multivessel operator guarantees that the goods are delivered in accordance with the following provisions of the agreement and documents. It is the document of the property and the proof of the transfer agreement. Multiple passport documents are divided into nondistributed form and distributed form. The nonbinding forms of the documents are the goods certificate and the transfer agreement certificate, but the documents are not transferable and the property right certificate. The form of transaction document refers to a combined 


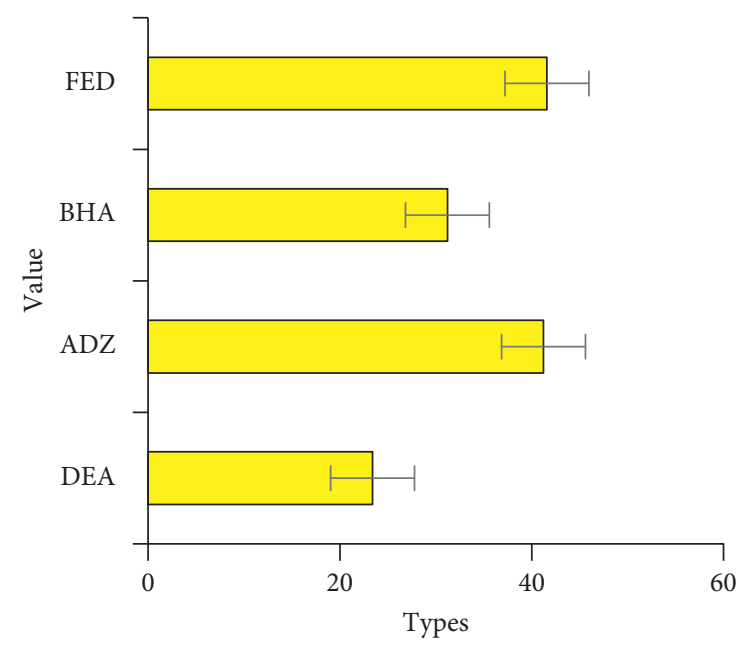

Total transport

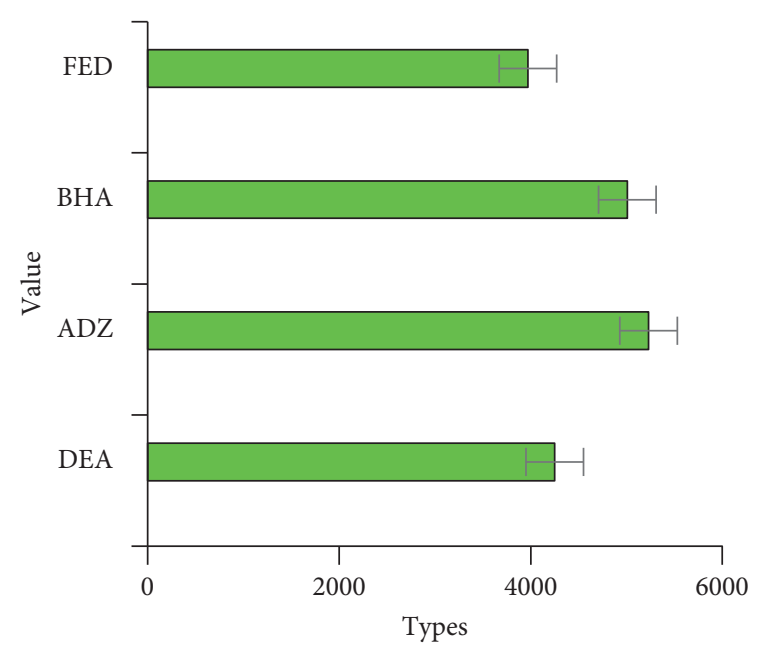

Net profit

FIGURE 11: The input and output data of enterprises.

TABLE 6: Input and output data.

\begin{tabular}{lcccccc}
\hline $\begin{array}{l}\text { Line } \\
\text { number }\end{array}$ & $\begin{array}{c}\text { Net profit } \\
\text { (USD) }\end{array}$ & $\begin{array}{c}\text { Goods in good } \\
\text { condition }\end{array}$ & $\begin{array}{c}\text { Annual growth rate of } \\
\text { traffic }\end{array}$ & $\begin{array}{c}\text { Total transit } \\
\text { time }\end{array}$ & $\begin{array}{c}\text { Total shipping } \\
\text { cost }\end{array}$ & $\begin{array}{c}\text { Enterprise organization } \\
\text { cost }\end{array}$ \\
\hline 1 & 24561 & 100 & 7.9 & 31 & 150080 & 2564 \\
2 & 30124 & 99.7 & 5.4 & 29 & 142300 & 2564 \\
3 & 29541 & 98.5 & 8.1 & 26 & 168000 & 2600 \\
\hline
\end{tabular}

transport document that has at least one passenger traveling by sea and can be used as the basis for the carriage of goods. The validity period of the tradable form of the multimodal passport is the same as that of the telegram. This kind of multimodal transportation is usually called a multimodal payment gateway.

\section{Conclusions}

Our country's container multivehicle logistics system cannot meet the requirements of the national econoour's multivehicle logistics system, and these inconveniences are not a clean transportation problem. The growth trend of public transportation in our country is that most of the container traffic is concentrated in developed coastal areas and major ports and lack of functionality. It is a part of the macro transmission control unit, which is mainly caused by the division of components and parts in the control system. Under this management system, transportation, warehousing, real estate, and foreign trade are their own, so the logistics of the entire society cannot be a whole. Therefore, to accelerate the rapid development of many large container vehicles and modern logistics, an effective institutional framework is needed to promote the development of modern logistics as a macro intervention. In terminal operations, container transportation is the most important part of all work. Almost all work is done around the container. Reasonably organizing all container-related information and developing management information systems can improve the efficiency of container trade, increase the level of automation of container processes, increase the distance between each connection point, and improve the overall operation level of port management. The possibility of having an advanced container terminal control system has become an important indicator for determining whether the port is to be developed. However, in the actual use process, because there is still a lack of understanding of the relevant professionalism, the design of the system and the solutions to certain problems are still not professional enough, and a deeper understanding is needed. In the actual use process, in the future, it will definitely consider the actual problems and modify it, and it will become more and more perfect.

\section{Data Availability}

No data were used to support this study.

\section{Conflicts of Interest}

The authors declare that there are no potential conflicts of interest in this study.

\section{Acknowledgments}

This work was supported by the Science and Technology Research Program of Chongqing Municipal Education Commission under Grant no. KJQN201903104.

\section{References}

[1] Z. Li, "Study on optimization of empty container transport in multimodal transport of containers," International Core Journal of Engineering, vol. 6, no. 2, pp. 28-36, 2020. 
[2] P. Grobelny, "Safety of Chemical - storage of hazardous materials on multimodal container terminals," Transportation Overview - Przeglad Komunikacyjny, vol. 2016, no. 3, pp. 28-34, 2016.

[3] M. Zhao, "Climate abnormal circulation based on monitoring system and marine logistics transportation management," Arabian Journal of Geosciences, vol. 14, no. 17, pp. 1-14, 2021.

[4] H. A. Rahman, J. Park, J. Park, and J. Suh, "Use of software agent technology in management information system: a literature review and classification," Asia Pacific Journal of Information Systems, vol. 29, no. 1, pp. 65-82, 2019.

[5] V. B. Vilkov, A. K. Chernykh, S. A. Nefed'Yev, and Y. D. Motorygin, "Transportation management of facilities for rescue operations upon disaster mitigation," International Journal of Civil Engineering \& Technology, vol. 9, no. 1, pp. 676-687, 2018.

[6] J. You, J. Wang, and J. Guo, "Real-time crash prediction on freeways using data mining and emerging techniques," Journal of Modern Transportation, vol. 25, no. 2, pp. 116-123, 2017.

[7] W. Zhu, M. M. Kamruzzaman, X. Sun, and X. Zhang, "Emergency decision support system for container logistics safety based on image processor," IEEE Access, no. 99, p. 1, 2020.

[8] P. Zheng, S. Quan, and W. Chu, "Analysis of market competitiveness of container Railway transportation," Journal of Advanced Transportation, vol. 2021, no. 3, pp. 1-8, 2021.

[9] L. Dong, G. Liu, X. Ye, and W. Wang, "Study on the design of container highway and Railway automatic transfer vehicle in ocean port," Polish Maritime Research, vol. 25, no. s3, pp. 5-12, 2018.

[10] A. Suárez-Alemán, J. Morales Sarriera, T. Serebrisky, and L. Trujillo, "When it comes to container port efficiency, are all developing regions equal?" Transportation Research Part A: Policy and Practice, vol. 86, no. apr, pp. 56-77, 2016.

[11] S. T. Huang, E. Bulut, and O. Duru, "Multi-dimensional service improvement under the multi-customer nature of container terminals," International Journal of Shipping and Transport Logistics, vol. 8, no. 2, pp. 194-222, 2016.

[12] B. Majumdar, S. C. Sarode, G. S. Sarode, and S. Patil, "Technology: artificial intelligence," British Dental Journal, vol. 224, no. 12, p. 916, 2018.

[13] T. Anan, H. Higuchi, and N. Hamada, "New artificial intelligence technology improving fuel efficiency and reducing $\mathrm{CO} 2$ emissions of ships through use of operational big data," Fujitsu entific \& Technical Journal, vol. 53, no. 6, pp. 23-28, 2017.

[14] M. Jaksic and M. Marinc, "Relationship banking and information technology: the role of artificial intelligence and FinTech," Risk Management, vol. 21, no. 1, pp. 1-18, 2017.

[15] C. H. Onwubere, "Geospatial data and artificial intelligence technologies as innovative communication tools for quality education and lifelong learning," EJOTMAS Ekpoma Journal of Theatre and Media Arts, vol. 7, no. 1-2, pp. 50-71, 2020.

[16] H. Horii, "Advancement of vehicle occupant restraint system design by integration of artificial intelligence technologies," International Journal of Transport Development and Integration, vol. 5, no. 3, pp. 242-253, 2021.

[17] F. Olan, J. Suklan, E. O. Arakpogun, and A. Robson, "Advancing consumer behavior: the role of artificial intelligence technologies and knowledge sharing," IEEE Transactions on Engineering Management, no. 99, pp. 1-13, 2021.

[18] A. V. Raknys, D. Gudelis, and A. Guogis, "The analysis of opportunities of the application of big data and artificial intelligence technologies in public governance and social policy," Socialiné Teorija Empirija Politika ir Praktika, vol. 22, no. 6, pp. 88-100, 2021.

[19] L. Cui, "A preliminary study on the management strategy of university personnel files based on artificial intelligence technology," Journal of Electronic Research and Application, vol. 5, no. 2, pp. 1-4, 2021.

[20] C. Ben, H. H. Li, T. Liu, Z. J. Wang, D. S. Cheng, and S. H. Zhu, "Advances in the research of artificial intelligence technology assisting the diagnosis of burn depth," Zhonghua shao shang za zhi = Zhonghua shaoshang zazhi = Chinese journal of burns, vol. 36, no. 3, pp. 244-246, 2020.

[21] Y. . Ding, "Performance analysis of public management teaching practice training based on artificial intelligence technology," Journal of Intelligent and Fuzzy Systems, vol. 40, no. 5, pp. 1-14, 2020.

[22] K.-Y. Kim, J. H. Jung, Y. A. Yoon, and Y. S. Kim, “Designing a performance certification test for automatic detection equipment based on artificial intelligence technology," Journal of Applied Reliability, vol. 20, no. 1, pp. 43-51, 2020.

[23] K. Xu, Z. Wang, Z. Zhou, and W. Qi, "Design of industrial internet of things system based on machine learning and artificial intelligence technology," Journal of Intelligent and Fuzzy Systems, vol. 40, no. 2, pp. 2601-2611, 2021.

[24] S. Lin, "Data mining artificial intelligence technology for college English test framework and performance analysis system," Journal of Intelligent and Fuzzy Systems, vol. 40, no. 2, pp. 1-11, 2020.

[25] E. A. Skvortsov, "Prospects of applying artificial intelligence technologies in the regional agriculture," Economy of Region, vol. 16, no. 2, pp. 563-576, 2020.

[26] Z. Lv, Y. Han, A. K. Singh, G. Manogaran, and H. Lv, "Trustworthiness in industrial IoT systems based on artificial intelligence," IEEE Transactions on Industrial Informatics, vol. 17, no. 2, p. 1, 2020.

[27] K. G. Srinivasa K G, B. J. Sowmya Bj, A. Shikhar, R. Utkarsha, and A. Singh, "Data analytics assisted internet of things towards building intelligent healthcare monitoring systems," Journal of Organizational and End User Computing, vol. 30, no. 4, pp. 83-103, 2018.

[28] H. Hamidi and M. Jahanshahifard, "The role of the internet of things in the improvement and expansion of business," Journal of Organizational and End User Computing, vol. 30, no. 3, pp. 24-44, 2018.

[29] E. Mohamed, "The relation of artificial intelligence with internet of things: a survey," Journal of Cybersecurity and Information Management, vol. 1, no. 1, pp. 30-24, 2020. 